\title{
EDITORIAL
}

\section{Tough decisions}

\section{Bhavin Jankharia}

Editor-in-Chief, Indian Journal of Radiology and Imaging, Bhaveshwar Vihar, 383 Sardar V P Road, Prarthana Samaj, Mumbai - 400004 , India.E-mail: editor@ijri.org

A recent judgment by the High Court in Mumbai has banned portable ultrasonography in private centers. There was a quote in one of the newspapers attributed to one of the judges that said that that even if there is a one in a million chance that a female fetus may be diagnosed and aborted because of portable ultrasound, then portable machines should be banned. We might as well then ban all ultrasound anyway.

The way in which officials across the country, in different states, cities, towns and districts, interpret the Preconception and Prenatal Sex Determination (PC-PNDT) Act makes no sense. There is no uniform implementation policy and a lot seems to depend on the whims and fancies of those in power. As a result, day-by-day, it is getting more and more difficult for individual radiologists to practice ultrasonography.

It is also difficult for individual radiologists to fight any of this. It is only when we all get together under the umbrella of our state chapters and the Indian Radiology and Imaging Association (IRIA), can something be done, if at all. Our energies now need to be focused on making sure that we, as radiologists, are not victimized and that the Act is implemented in spirit uniformly across the country.
The strangest part of the Act, however, seems to be that neither the people (lay people) who want to know the sex of their unborn children nor those who actually perform the abortions (gynecologists) seem to be getting into any trouble.

The May 2012 issue will be a special issue on the PC-PNDT act. Drs. Sanjeev Mani and Jignesh Thakker are the guest editors of this special issue. I also invite all the members of the IRIA to contribute letters, articles and their perspectives on this subject. Needless to say, all submissions have to be as per the "Guidelines for Authors."

Once in a while, the IJRI also gets a letter or two regarding issues between an individual radiologist and a vendor company. This is invariably related to machines not working or malfunctioning and problems with service and service contracts. There are some basic rules to be followed when purchasing equipment, such as buying only from reputed vendors, making sure that service contracts are understood in detail, etc. In 2012, we will publish a few articles on this subject to try and bring out the do's and don'ts of equipment purchasing and maintenance. If any reader would like to contribute, the IJRI would be more than happy to go through these submissions!

\begin{tabular}{|l|l|}
\hline \multicolumn{2}{|c|}{ Access this article online } \\
\hline Quick Response Code: & \\
\hline & Website: \\
\hline & www.ijri.org \\
\cline { 2 - 3 } & DOI: \\
\hline
\end{tabular}

